\title{
The role of health literacy in parents' decision making in children's sporting participation
}

\author{
Stefania Velardo \\ School of Education, Flinders University
}

Sam Elliott

School of Education, Flinders University

Shaun M Filiault

School of Education, Flinders University

\author{
Murray JN Drummond \\ School of Education, Flinders University
}

\begin{abstract}
The contemporary concept of health literacy has received heightened attention within the academic community over the last decade. Health literacy, which is related to the acquisition, understanding and application of health-related information (Jordan, Buchbinder and Osborne 2010), has been acknowledged as a key public health goal within Australia. Health literacy is particularly important where parents and children are concerned, as parents play a key role in recommending or discouraging activities that may impact on children's physical health, such as sport. A health literacy approach may reshape parental motivations towards the holistic outcomes of sporting engagement, thereby promoting a healthier approach to sport participation. This is fundamental, given the current orientation towards a competitive sports model of participation within Australia, even for those participating at an amateur level. At present, improving social awareness of the physical health benefits of junior sport participation is a major challenge for communities, as parents are motivated by a combination of factors. Sport
\end{abstract}


sociology literature suggests that social health is the primary beneficiary and motivator of junior sport participation, which encompasses the formation and development of friendships and communication skills. For parents, another key motivational factor for junior sport participation is the importance placed on winning. However, the fundamental benefits of junior sport involvement extend beyond the competitively oriented goals that are often enforced by parents. Consequently, there is a concern that parents who lack a holistic understanding of the physiological, biomechanical and social benefits of junior sport may impact on sport discontinuation. This paper will provide discussion around the importance of taking a health literacy approach towards junior sporting participation rather than the competitive model that currently dominates sport in Australian culture. It will highlight the health and broader social benefits of taking such an approach.

\section{Introduction}

The role of physical activity and leisure pursuits during childhood is important to the development of the whole child and not merely based on physical benefits (Malina 2009). Junior sporting participation plays a significant part in this physical activity and leisure. However, there is a fundamental question that needs to be addressed. Who decides whether a child should participate in sport and in which sport(s) should they engage? Clearly parents play a major role in this decision-making process. However, this is largely based upon socially constructed notions underpinned by culture, history and education. This paper will identify key issues in arguing a case for the development of parental decision making in junior sports around health literacy.

\section{Health benefits of sport}

Research evidence suggests youth participation in sport engenders numerous benefits for the physical, psychological and social health of the young person. Indeed, the health-related advantages of sport are wide-ranging, from obesity prevention to academic enhancement, as briefly reviewed below.

\section{Medical and physical benefits}

It is widely accepted that physical activity, including involvement in sports, may help mitigate the health problems associated with obesity, such as heart disease, type 2 diabetes and cancers (as reviewed by Filiault 2008). Additionally, regular physical activity may reduce the risk of an individual ever becoming obese, particularly when regular exercise becomes habitual in childhood. For example, in a study of 780 European children, Ruiz and colleagues (2006) illustrated that regular, high-intensity exercise was negatively correlated with body fat accumulation. Similarly, Cruz et al. (2005) reported that weight-bearing exercise reduces insulin resistance in children and adolescents. Accordingly, the American Heart Association (Hayman et al. 2004) recognises regular physical activity as a crucial component to maintaining youth health and preventing obesity and related syndromes. 
Beyond the caloric expenditure associated with physical activity, sporting participation may enhance skeletal and muscular function among young people. It is well documented that weight-bearing exercise undertaken in childhood may facilitate improved bone density, which may persist into adulthood (e.g. Lloyd et al. 2000; Stewart et al. 2005). Similarly, involvement with exercise may facilitate improvements in muscular coordination (Ewing et al. 2002). Improved motor control may provide enhanced confidence to persist in sport and exercise throughout the lifespan (Carroll and Loumidis 2001).

\section{Psychological and social benefits}

Beyond the physical benefits previously described, physical activity may generate psychological and social benefits for children. Youth involved with sport report greater emotional wellbeing (Steptoe and Butler 1996), improved self-esteem (Fox 2000), and may exhibit less risk for affective and anxiety disorders (Bailey 2006). Finally, sporting participation, particularly in school, may enhance academic performance and general attitudes towards schooling (Bailey 2006).

There are numerous social benefits that sport may provide for its participants. Importantly, not all social aspects of sport are positive despite the rhetoric that often emerges within contemporary media around the benefits of sport. For example, sport is a site for gender construction and reconstruction (Drummond 1996). However, there are issues associated with marginalisation and stigmatisation around gender and sexualities within many sporting environments that can make the sporting experience a negative one and therefore influence participants to abstain or 'drop out' of sport altogether. Therefore when discussing the social benefits of sport it must be tempered with the notion that not everything in sport is a socially enjoyable experience. Indeed, there are many pleasurable experiences that sport can provide including the building of self-esteem and friendships, as well as a sense of belonging among a team of peers, whether it be competing within a team or competing as an individual against peers (Wiersma and Fifer 2008).

\section{The role of parents}

Parents also play an important part in the social experience of junior sport. As Coakley (2006) suggested, both mothers and fathers are integral to this process, despite often perpetuating traditional gender roles within sports which may emerge from identifiable dispositions and practices related to family life and parenting. That is, mothers wash the uniforms and work in the canteen while fathers either coach or engage with the coach; otherwise they may be involved with the team at an administrative level. Regardless, where children are concerned, parents recognise the importance of the socialisation component of the parent-child relationship. Such an ideology needs to be taken into consideration when discussing the issues associated with parental behaviours and children's sporting participation.

\section{Parental motivations}

Parents are recognised as a major contributing factor to children's ability to, and desire to, maintain involvement in sports (Harwood and Knight 2009; Keegan et al. 
2009). Accordingly, parental beliefs about sport and the benefits of sporting participation are paramount in determining whether a child will persist in sport, and receive the multitude of bio-psychosocial benefits intrinsic to sporting participation.

Improving social awareness of the benefits of physical activity participation to improve general health and wellbeing is a major challenge for public health policy makers, health care providers and communities (Australian Institute of Health and Welfare 2000). Subsequently, the promotion of regular physical activity has gained considerable momentum in response to public health concerns (Carroll and Loumidis 2001; Ornelas, Perreira and Ayala 2007; Trost et al. 2003). However, Kirk et al. (1997) argued that a principal motivator for junior sport participation in Australia is perceived social experience rather than potential physiological and psychological benefits. This perspective was maintained by Wiersma and Fifer (2008), who were 'surprised' when only one parent out of 55 considered physical health outcomes as a perceived benefit of junior sport participation during focus group discussions. In contrast, numerous social benefits, which included the development of responsibility for one's own play, learning to listen and follow directions, maintaining perspective, establishing friendships and creating long lasting memories, were identified as key to motivation and sport continuation.

Parents also recognise the formation and maintenance of friendships as a social construct that influences children's motivation and participation in junior sport (Keegan et al. 2009; Ullrich-French and Smith 2009). Fredricks and Eccles (2004) emphasised the influence of parents in junior sport and further asserted that children's participation is a manifestation of parental beliefs and behaviours surrounding the role and purpose of sport. They claimed that circumstances such as education, income, marital status, employment status, cultural traditions and neighbourhood resources shape parental behaviours and attitudes, which inadvertently affect children's motivation. They also corroborated the seminal research of Woolger and Power (1993), who stated that parental behaviours can have an impact on children's intrinsic motivation by means of support, involvement, expectations, rewards, punishments and directiveness.

While parents recognise the social benefits of junior sport participation, they have also been shown to place significant emphasis on 'winning'. Defrancesco and Johnson (1997) conducted a study that investigated parent and child perceptions towards winning and losing within a junior sporting environment. They reported that 33.4 per cent of parents surveyed stated that it was 'very important' for their child to win while a further 64.4 per cent of parents perceived winning to be 'moderately important'. The perpetuation of winning at the junior level has also been documented by Gould et al. (2006), in their investigation focusing on junior tennis parents. They reported that parents over-emphasised winning, held unrealistic expectations, openly criticised their children and were involved in physical confrontations with other parents at various stages during the season (Gould et al. 2006).

Moreover, a retrospective study conducted by Fraser-Thomas and Cote (2009) explored the positive and negative developmental experiences of adolescent 
competitive swimmers. For a select few participants, parents influenced the junior sport experience by bribing their child to excel or stay involved in the sport. In some instances, parents explicitly reminded the child of the family sacrifices made to enable their participation, and their consequent expectations of ongoing participation and competitive success. Furthermore, participants reported feeling stressed in response to parental pressure to 'excel in sport', and the inherent expectation to win (Fraser-Thomas and Cote 2009, p. 16). These findings draw attention to key issues that surround participation other than any perceived physical or psychological benefits.

\section{Health literacy}

The concept of health literacy has received heightened attention within the academic community over the last decade. Health literacy, which has been identified as a key determinant of health, is broadly related to the acquisition, understanding and application of health-related information (Jordan et al. 2010). In an Australian context, health literacy has been acknowledged as an important public health goal, as consumers need to be equipped with adequate skills to 'understand and use information about how to stay healthy [and] ... find their way around the health system' (National Health and Hospitals Research Commission 2009, p. 122). Future strategies to develop consumer health literacy are particularly important, given that results from the 2006 National Literacy Survey indicated that approximately 9 million (59\%) Australians lacked basic health literacy skills (Australian Bureau of Statistics 2008).

Early definitions of health literacy predominantly focused on people's ability to read, write and understand written and oral information in health-related settings (Jordan et al. 2010; Peerson and Saunders 2009). Over time, however, a broader conceptualisation of health literacy has emerged, which is not limited to the fields of literacy and numeracy. Nutbeam provided a broader definition of the term within the World Health Organization health promotion glossary, as follows: 'Health literacy represents the cognitive and social skills which determine the motivation and ability of individuals to gain access to, understand and use information in ways which promote and maintain good health' (1998, p. 357).

Nutbeam (2000, p. 265) also proposed a three-tiered classification system to categorise different components of health literacy. Level 1 is 'functional health literacy' which is concerned with the use of basic literacy skills, such as reading and writing, to understand and follow simple health messages. Level 2 is 'interactive health literacy', which focuses on the ability to understand and act independently on information for prevention and self-management of health conditions. In contrast, level 3 focuses on 'critical health literacy', which refers to critically analysing information and improving individual and community capacity for social action to address social, economic and environmental barriers to health.

Peerson and Saunders elaborated on Nutbeam's definition to stress the importance of an individual's ability to 'understand and act on messages that are central to making critical judgments and decisions not only in health-related settings, but also about health' (2009, p. 286). This conceptualisation acknowledges health literacy as 
an important life skill, as it includes individuals who are not patients in health care settings and focuses on health-related decision making that is undertaken in everyday life.

\section{Health literacy and parental motivations for sport}

It is evident from the literature about parental motivations for child sporting participation that the health benefits of sport are not the primary factor considered when enrolling a child in sporting activities. Indeed, it is the ancillary aspects of sporting culture, particularly the notion of winning and competition, that serve as motivators (Hellstedt 1990). While those factors may encourage some children to participate in sport over the long term, it is unlikely that those competitive aspects can encourage most children to maintain involvement. Indeed, as Anderson (2009) noted, sporting cultures, as currently constructed, are inherently closed, tiered systems of participation. That is, only those who 'succeed' in sport are allowed to continue to participate, and often it is only these sporting successes who want to participate. With the exception of participants who specifically set out to play 'social sport', all others are either cut from participation or, as is more often the case, voluntarily opt out of a system that fails to provide sufficient motivation to continue. Accordingly, 'winning' as a motivating factor to play sport is not only unable to engender majority participation, but it actually does the opposite by rewarding a select minority (Anderson 2009). This nature of sport is reflected by the fact that children with low perceptions of ability, who fail to succeed, are actually those who are most likely to ‘quit’ sport (Cervelló, Escartí and Guzmán 2007). This is certainly a perplexing dilemma given the emphasis Australians place on junior sport and a winning competitive culture.

Often, the desire to win does not find its origin with the child, but rather the parent, as noted above (Shields et al. 2005; Gould et al. 2006). This parental desire to win may reflect contemporary discourse in parenting, which suggests that to be a good parent one must not only encourage youth sporting involvement, but also stress sporting success (Coakley 2006). This motivation creates a logical disconnect between the act of sport and the outcome of sport. That is, the reason for sporting engagement is not always related to the physical act of playing. Rather, the motivation becomes contingent upon a culturally valued potential outcome. The physical activity in sport therefore becomes an incidental conduit by which to win and be a good parent.

The argument can be made that the competitive aspects of junior sport as a primary motivator for initial sporting involvement is insufficient to guarantee lifetime engagement. Furthermore, it devalues the benefits of being physically active, regardless of the culturally constructed 'result' of that participation. Rather than placing the emphasis on such a tenuous and circumstantial result as winning, it may be more sustainable to re-orient motivation to those aspects of sport that have a greater likelihood of occurring in each session. That is, sporting motivation should focus upon the physiological, psychological and social tasks that each outing requires. If that re-orientation occurs, then the focus becomes intrinsic to the actual doing of sport, rather than the successful judging of sport. While one of those factors can be guaranteed, the other certainly cannot. Thus, a focus upon the benefits of 
doing sport becomes a sustainable means by which to motivate participation, which does not depend upon failing individuals. Each session can become successful simply by playing.

Accordingly, an ideological and structural shift must occur in sport at every level of junior sporting participation. Concepts of winning and losing need to be challenged and de-emphasised to allow for a more open, benefits-oriented paradigm to take shape. The ideological shift needs to take place both at the organisational level of leagues and associations, but also at the parental level. While leagues and associations need to re-orient the focus from developing ladders to developing people, parents need to re-orient their motivations from creating elite sporting champions to developing healthy children that have the capacity to take healthoriented skills through to adulthood. These shifts in attitudes will almost certainly be reflected in children given the profound influence parental attitudes have on children's experiences in sport.

We suggest that a health literacy approach to youth sport is therefore required. It becomes imperative that parents attain all three levels of health literacy conceptualised by Nutbeam (2000). At a functional level, parents need to understand not only the psychological implications of a winning orientation on their children. More importantly, parents must become aware of the numerous physiological, psychological and social benefits engendered through continued sporting involvement. At an interactive level, parents need to communicate these benefits to their children by serving as role models. In accordance with a broader conceptualisation of health literacy, it is important to empower parents by developing their skills and capabilities (Kickbusch 2001). For example, parents must develop an understanding of how to de-emphasise game results, and instead focus upon the specific acts related to participating. These attitudes will almost certainly be reflected in children's behaviour.

At the highest level, a critical approach to health literacy is required. If sporting cultures, as well as leagues and associations, are to change, it will require a concerted effort by parents to facilitate that change by pressuring sport organisations to undertake a shift in ideology from a professional to developmental perspective. This critical health literacy, however, is first contingent upon parents developing an understanding of the wide-ranging benefits of sport, and the problems associated with a winning perspective.

We recognise that health literacy is highly correlated with various demographic features, especially race and socioeconomic status (SES). Those individuals who are most disadvantaged are likely to have lower levels of health literacy (Tokuda et al. 2009). Ironically, it is often individuals from low SES communities who are also most likely to embrace the competitive aspects of sport, even at the junior level. In these communities, sometimes sport is viewed as a means by which to achieve greater cultural currency (Eitle and Eitle 2002). While these factors pose a considerable and important barrier to shifting cultural attitudes about sport, they do not eliminate the need for such a shift to occur. Instead, these challenges re-iterate the need for health policy to be developed that begins to mitigate the influence of 
SES on health literacy, and a re-structuring of health opportunity and resources in a manner that does not disadvantage those who are already the most economically disadvantaged.

\section{Conclusion}

Given the concern about parents' perceptions of the benefits of children's sport participation, the purpose of this paper was to highlight the potential role of health literacy in reshaping parental motivations towards the holistic outcomes of sporting engagement. Interventions that address the three tiers of health literacy may enhance parents' understanding of the physiological, psychological and social outcomes of physical activity, thereby enabling them to further promote these aspects of sporting involvement.

Using health literacy as a heuristic by which to re-conceptualise youth sport thus allows an orientation towards junior associations that emphasises the aspects of sport that all participants can enjoy, regardless of skill, while simultaneously deemphasising those aspects that limit participation to only the most skilled. Schools may be an ideal venue through which to disseminate these health-oriented views toward sport. Physical education classes that reinforce these participation-oriented views towards sport will certainly influence child attitudes. In turn, through adopting a health literacy approach and a health-promoting school philosophy towards child and community health, parents can become incorporated into the school ethos, thereby bringing these attitudes into the home and community. This alternative approach to junior sport participation may therefore generate more positive experiences for children, which may increase the likelihood that they will continue to participate in sport throughout their lives.

\section{References}

Anderson, E 2009, 'The maintenance of masculinity among the stakeholders of sport', Sport Management Review, vol. 12, pp. 3-14.

Australian Bureau of Statistics 2008, Health Literacy, Australia, Cat. No. 4233.0, ABS, Canberra.

Australian Institute of Health and Welfare 2000, Physical activity patterns of Australian adults, AIHW, Canberra.

Bailey, R 2006, 'Physical education and sport in schools: a review of benefits and outcomes', Journal of School Health, vol. 76, pp. 397-401.

Carroll, B and Loumidis, J 2001, 'Children's perceived competence and enjoyment in physical education and physical activity outside school', European Physical Education Review, vol. 7, no. 1, pp. 24-43. 
Cervelló, EM, Escartí, A and Guzmán, JF 2007, 'Youth sport dropout from the achievement goal theory', Psicothema, vol. 19, no. 1, pp. 65-71.

Coakley, J 2006, 'The good father: parental expectations and youth sport', Leisure Studies, vol. 25, no. 2, pp. 153-163.

Cruz, ML, Shaibi, GQ, Weigensberg, MJ, Spruijt-Metz, D, Ball, GD and Goran, MI 2005, 'Pediatric obesity and insulin resistance: chronic disease risk and implications for treatment beyond body weight modification', Annual Review of Nutrition, vol. 25, pp. 435-468.

Defrancesco, C and Johnson, P 1997, 'Athlete and parent perceptions in junior tennis’, Journal of Sport Behavior, vol. 20, no. 1, pp. 29-36.

Drummond, M 1996, The social construction of masculinity as it relates to sport: an investigation into the lives of elite level athletes competing in individually oriented masculinised sports, PhD thesis, Edith Cowan University, Perth.

Eitle, TM and Eitle, DJ 2002, 'Race, cultural capital, and the educational effects of participation in sports', Sociology of Education, vol. 75, no. 2, pp. 123-146.

Ewing, ME, Gano-Overway, LA, Branta, CF and Seefeldt, VD 2002, 'The role of sports in youth development' in Paradoxes of youth and sport, ed. M Gatz, MA Messner and SJ Ball-Rokeach, State University of New York Press, Albany, NY, pp. 31-48.

Filiault, SM 2008, 'Exercise for obesity treatment and prevention: current perspectives and controversies' in Obesity: causes, mechanisms, prevention and treatment, ed. E Blass, Sinauer Associates, Sunderland, pp. 243-280.

Fox, K 2000, 'The effects of exercise on self-perceptions and self esteem', in Physical activity and psychological well-being, ed. S Biddle, K Fox and S Boutcher, Routledge, London, pp. 88-117.

Fraser-Thomas, J and Cote, J 2009, 'Understanding adolescents' positive and negative developmental experiences in sport', The Sport Psychologist, no. 23, pp. 3-23.

Fredricks, J and Eccles, J 2004, 'Parental influences on youth involvement in sport' in Developmental sport and exercise psychology: a lifespan perspective, ed. M Weiss Fitness Information Technology, West Virginia, pp. 145-164.

Gould, D, Lauer, L and Rolo, C 2006, 'Understanding the role parents play in tennis success: a national survey of junior tennis coaches', British Journal of Sports Medicine, vol. 40, pp. 632-636. 
Harwood, C and Knight, C 2009, 'Stress in youth sport: a developmental investigation of tennis parents', Psychology of Sport and Exercise, vol. 10, no. 4, pp. 447-456.

Hayman, LL, Williams, CL, Daniels, SR, Steinberger, J, Paridon, S, Dennison, BA et al. 2004, 'Cardiovascular health promotion in schools', Circulation, vol. 110, pp. 2266-2275.

Hellstedt, J 1990, 'Early adolescent perceptions of parental pressure in the sport environment’, Journal of Sport Behaviour, vol. 13, no. 3, pp. 135-144.

Jordan, J, Buchbinder, R and Osborne, R 2010, 'Conceptualising health literacy from the patient perspective', Patient Education and Counseling, vol. 79, no. 1, pp. 36-42.

Keegan, R, Harwood, C, Spray, C and Lavallee, D 2009, ‘A qualitative investigation exploring the motivational climate in early career sports participants: coaches, parent and peer influences on sport motivation', Psychology of Sport and Exercise, vol. 10, no. 3, pp. 361-372.

Kickbusch, I 2001, 'Health literacy: addressing the health and education divide', Health Promotion International, vol. 16, no. 3, pp. 289-287.

Kirk, D, O’Connor, A, Carlson, T, Burke, P, Davis, K and Glover, S 1997, ‘Time commitments in junior sport: social consequences for participants and their families', European Journal of Physical Education, vol. 2, no. 1, pp. 51-73.

Lloyd, T, Chinchilli, VM, Johnson-Rollings, N, Kieselhorst, K, Eggli, DF and Marcus, R 2000, 'Adult female hip bone density reflects teenage sportsexercise patterns but not teenage calcium intake', Pediatrics, vol. 106, pp. 40-44.

Malina, R 2009, 'Children and adolescents in the sport culture: the overwhelming majority to the select few', Journal of Exercise Science \& Fitness, vol. 7, no. 2, pp. S1-10.

National Health and Hospitals Reform Commission 2009, A healthier future for all Australians: final report June 2009, Commonwealth of Australia, Canberra.

Nutbeam, D 1998, 'Health promotion glossary', Health Promotion International, vol. 13, no. 4, pp. 349-364.

Nutbeam, D 2000, 'Health literacy as a public health goal: a challenge for contemporary health education and communication strategies into the 21st century', Health Promotion International, vol. 15, no. 3, pp. 259-267. 
Ornelas, IJ, Perreira, KM and Ayala, GX 2007, 'Parental influences on adolescent physical activity: a longitudinal study', International Journal of Behavioural Nutrition and Physical Activity, vol. 4, no. 3, pp. 1-10.

Peerson, A and Saunders, M 2009, 'Health literacy revisited: what do we mean and why does it matter?' Health Promotion International, vol. 24, no. 3, pp. 285296.

Ruiz, JR, Rizzo, NS, Hurtig-Wennlof, A, Ortega, FB, Wurnberg, J and Sjostrom, M 2006, 'Relations of total physical activity and intensity to fitness and fatness in children: the European Youth Heart Study', American Journal of Clinical Nutrition, vol. 84, pp. 299-303.

Shields, D, Bredemeier, BL, LaVoi, NM and Power, FC 2005, 'The sport behaviour of youth, parents and coaches', Journal of Research in Character Education, vol. 3, no. 1, pp. 43-59.

Steptoe, AS and Butler, N 1996, 'Sports participation and emotional well-being in adolescents’, The Lancet, vol. 347, no. 9018, pp. 1789-1792.

Stewart, KJ, Bacher, AC, Hees, PS, Tayback, M, Ouyang, P and Jan de Baur, S 2005, 'Exercise effects on bone mineral density: relationships to changes in fitness and fatness', American Journal of Preventative Medicine, vol. 28, pp. 453-460.

Tokuda, Y, Doba, N, Butler, JP and Paasche-Orlow, MK 2009, 'Health literacy and physical and psychological wellbeing in Japanese adults', Patient Education and Counselling, vol. 75, no. 3, pp. 411-417.

Trost, SG, Sallis, JF, Pate, RR, Freedson, PS, Taylor, WC and Dowda, M 2003, 'Evaluating a model of parental influence on youth physical activity', American Journal of Preventative Medicine, vol. 25, no. 4, pp. 277-282.

Ullrich-French, S and Smith, A 2009, 'Social and motivational predictors of continued youth sport participation', Psychology of Sport and Exercise, vol. 10, no. 1, pp. 87-95.

Wiersma, L and Fifer, A 2008, “"The schedule has been tough, but we think it's worth it”: the joys, challenges, and recommendations of youth sport parents', Journal of Leisure Research, vol. 40, no. 4, pp. 505-530.

Woolger, C and Power, TG 1993, 'Parents and sport socialization: views from the achievement literature’, Journal of Sport Behaviour, vol. 16, pp. 171-189. 